\title{
Prolactin Upregulates Female-Predominant P450 Gene Expressions and Downregulates Male-Predominant Gene Expressions in Mouse Liver
}

\author{
Yuya Sato, Yoshikatsu Kaneko, Takamasa Cho, Kei Goto, Tadashi Otsuka, Suguru Yamamoto, \\ Shin Goto, Hiroki Maruyama, and Ichiei Narita
}

Division of Clinical Nephrology and Rheumatology (Y.S., Y.K., T.C., K.G., T.O., S.Y., S.G., I.N.) and Department of Clinical Nephroscience (H.M.), Niigata University Graduate School of Medical and Dental Sciences, Asahimachi-dori, Niigata, Japan

Received December 15, 2016; accepted March 17, 2017

\begin{abstract}
Prolactin is a polypeptide hormone with over 300 separate biologic activities. Its serum level is increased during pregnancy and lactation, and it has been reported that pregnancy and lactation affect drug and steroid metabolism in mice and humans. Several studies reported that pregnancy or lactation influences liver cytochrome P450 (P450) expression and its activity, affecting the biosynthesis of steroids and xenobiotics through growth hormone or sex hormones; however, the role of prolactin as the regulator of liver $P 450$ expression has not been elucidated so far. In the present study, we focused on prolactin as the regulator of expression of liver sexpredominant genes, including P450s. To investigate the role of prolactin in the hepatic gene expressions, pCAGGS expression vector containing mouse prolactin cDNA was transfected by hydrodynamic injection into both male and female mice. Hyperprolactinemia
\end{abstract}

phosphorylated signal transducer and activator of transcription $\mathbf{5}$ in the liver and augmented female mouse liver mRNA expression of Сyp3a16, Сyp3a41, Сyp3a44, Cyp2b9, and prolactin receptor genes, whose expressions were female-predominant in hepatocytes. Moreover, liver expression of male-predominant genes such as Cyp2d9, Cyp7b1, Mup1, and Alas2 were reduced in male mice with hyperprolactinemia. The serum levels of conventional regulators of hepatic gene expressions, growth hormone, and testosterone were not affected by hyperprolactinemia. We demonstrated that prolactin upregulated female-predominant genes in female mice and downregulated male-predominant genes in male mice. We conjecture that higher concentration of prolactin would alter steroid and xenobiotic metabolisms by modulating hepatic $\boldsymbol{P} 450$ gene expressions during pregnancy and lactation.

\section{Introduction}

Prolactin is a polypeptide hormone that is mainly synthesized in and secreted from the lactotrophs cells of the anterior pituitary gland, and it regulates lactation, luteotrophic actions, and reproductive and parental behavior. During pregnancy prolactin has important roles in the development of mammary epithelium, and the maintenance and secretory activity of the corpus luteum in some mammals, particularly rodents. Moreover, prolactin has over 300 separate biologic activities and is synthesized and secreted from various organs and tissues, such as hypothalamus, mammary gland, and immune cells (Freeman et al., 2000; Bachelot and Binart, 2007). Prolactin is secreted on proestrus evening in response to ovarian estradiol and returns to basal levels the next morning during the 4-day estrous cycle of the female rat. Prolactin secretion is also transiently elevated by mating stimulus on the uterine cervix as a nocturnal and a diurnal surge in female rat (Freeman et al., 2000; Kennett and McKee, 2012). The diurnal or nocturnal surges of prolactin then recur for 10 days if the mating is fertile and results in pregnancy, and the surges of prolactin cease after

This work was partly supported by JSPS KAKENHI [Grant JP24591191] and NOVARTIS Foundation for Gerontological Research.

https://doi.org/10.1124/dmd.116.074658. day 10 of pregnancy owing to the negative-feedback action of placental lactogen, which is mainly secreted from placenta and has structural and functional similarity to pituitary prolactin (Voogt et al., 1982; Tonkowicz et al., 1983; Corbacho et al., 2002). After birth, suckling stimulus induces prolactin secretion again. In rats blood prolactin concentrations begin to rise within 1-3 minutes of initiation of nursing, reach $200-300 \mathrm{ng} / \mathrm{ml}$ within $10-15$ minutes, and are sustained at a constant level as long as nursing continues (Grosvenor and Whitworth, 1974; Moore, 1987).

It has been reported that hepatic drug metabolism is influenced by sex differences, and pregnancy and lactation also affect drug and steroid metabolism in mice and humans. Several studies reported that liver cytochrome P450 (P450) expression and activity were different between female and male, and were altered during pregnancy, delivery, and lactation (He et al., 2005; Tracy et al., 2005; Zhang et al., 2008; Waxman and Holloway, 2009; Koh et al., 2011). All known mammalian P450 enzymes are membrane-associated proteins, located either in the endoplasmic reticulum or in the inner membrane of mitochondria (Sugimoto and Shiro, 2012). They play central roles in the biosynthesis of such bioactive compounds as sterols, steroid hormones, eicosanoids, and vitamins, and in the oxidative metabolism of a wide range of medicines and the detoxification of xenobiotics (Waxman et al., 1988; Shimada et al., 1994; Sugimoto and Shiro, 2012). The expression of

ABBREVIATIONS: GH, growth hormone; GHR, growth hormone receptor; Igf, insulin-like growth factor; Jak, Janus kinase; Mup, major urinary protein; P450, cytochrome P450; PCR, polymerase chain reaction; PGH, placental growth hormone; PrIR, prolactin receptor; Stat, signal transducer and activator of transcription; $\mathrm{TT}$, total testosterone. 
many hepatic genes, including the $P 450$ superfamily, has been reported to be influenced by sex-specific patterns of growth hormone $(\mathrm{GH})$ secretion, namely pulsatile secretion in males and continuous secretion in females, resulting in sexual dimorphism of hepatic gene transcription (Norstedt and Palmiter, 1984; Waxman and O'Connor, 2006). These sexdependent differences in gene expression are most prominent in rodents but were also observed in humans (Waxman and Holloway, 2009). These sex-predominant hepatic genes are classified into four categories: male class I genes require pituitary hormones, principally GH pulse, for full expression and are therefore decreased in expression after hypophysectomy or continuous GH treatment; male class II genes are primarily regulated by the repressive actions of the female GH pattern in both male and female rodents and do not require $\mathrm{GH}$; female class I genes require continuous GH exposure and are decreased in expression after hypophysectomy or GH pulse; and female class II genes are also increased in expression after hypophysectomy, and are suppressed by GH pulse replacement (Wauthier and Waxman, 2008; Waxman and Holloway, 2009; Wauthier et al., 2010). Pulsatile GH binding to GH receptor (GHR) activates the GHR-associated tyrosine kinase Janus kinase (Jak) 2, which in turn phosphorylates the cytoplasmic domain of GHR at multiple sites, generating docking sites for signal transducer and activator of transcription (Stat) 5b, resulting in the nuclear translocation and induction of target gene transcription (Waxman and O'Connor, 2006). In addition to GH, several other physiologic hormones such as placental GH (PGH) or estrogens regulate liver $P 450$ expression (Waxman and O'Connor, 2006; Zhang et al., 2008; Waxman and Holloway, 2009). However, the role of prolactin as the regulator of liver $P 450$ expression and other sex-different hepatic genes has not been elucidated so far. In the present study, we focused on prolactin as the regulator of liver sex-predominant genes by using male and female mice with hyperprolactinemia induced by gene transfer of murine prolactin cDNA into hepatocytes, and revealed the influence of hyperprolactinemia on hepatic gene expression.

\section{Materials and Methods}

Animals. Male and female C57BL/6J mice at 10-12 weeks of age were purchased from Charles River Japan (Yokohama, Japan) and maintained in our animal facility until the implementation of the experiments. They were individually housed in cages and kept under 12-hour light and dark cycle with free access to standard chow and water. All mice were sacrificed to collect serum and liver samples 2 days after the hydrodynamic injection of expression plasmid vector. Twenty milligrams of pentobarbital was injected intraperitoneally for anesthesia before sacrifice. All the animal experiments were conducted in compliance with the protocol reviewed by the Institutional Animal Care and Use Committee and approved by the President of Niigata University (permit number: \#28 Niigata Univ. Res. 289-2).

Construction of Expression Vectors and Hydrodynamic Injection. The pCAGGS vector was kindly provided by Dr. Miyazaki (Niwa et al., 1991). The coding sequence of mouse prolactin was inserted into the pCAGGS vector at XhoI site. Insert fragment was generated by DNA synthesis, and mock vector was used as a control. Plasmids were purified in an endotoxin-free environment using an EndoFree Plasmid Maxi Kit (Qiagen, Hilden, Germany) and then dissolved in sterile phosphate-buffered saline ( $5 \mu \mathrm{g}$ of plasmid DNA per $1 \mathrm{ml}$ ). Each expression vector was transfected into mouse liver by the hydrodynamic method (Liu et al., 1999). A mouse was placed in a holding device and $2 \mathrm{ml}$ of plasmid DNA solution (10 $\mu \mathrm{g}$ of plasmid DNA per mouse) was injected rapidly via the tail vein using a 30-gauge needle. Total DNA was extracted from the liver of each mouse treated with pCAGGS vector using a DNeasy Blood and Tissue Kit (Qiagen), and the pCAGGS common sequence and inserted mouse prolactin CDNA were confirmed with polymerase chain reaction (PCR). Total RNA was also extracted from the liver and cDNA was synthesized by reverse transcriptase and amplified by PCR to detect GAPDH and mouse prolactin. The primer sequences are shown in Table 1.

Measurement of Specific Hormones. Prolactin and GH levels in the mice sera were measured using ELISA kits for mouse prolactin and GH, respectively (Cloud-Clone, Houston, TX). Serum total testosterone (TT) concentration was measured by the electrochemiluminescence immunoassay method (SRL Inc., Tokyo, Japan).

Western Blot Analysis. Liver lysate or serum samples were separated using SDS-PAGE and transferred onto polyvinylidene difluoride membrane. The membrane was blocked with a Western Blocking Reagent (Roche, Manheim, Germany) for 30 minutes at room temperature. The blocked membrane was incubated overnight at $4^{\circ} \mathrm{C}$ with goat polyclonal anti-prolactin receptor (PrlR) antibody (AF1167, $0.1 \mu \mathrm{g} / \mathrm{ml}$; R\&D Systems, Minneapolis, MN), rabbit polyclonal anti-Stat5 antibody (9363S, $0.1 \mu \mathrm{g} / \mathrm{ml}$; Cell Signaling Technology, Danvers, MA), rabbit monoclonal anti-phospho-Stat5 (Tyr694) antibody (D47E7, $0.1 \mu \mathrm{g} / \mathrm{ml}$; Cell Signaling Technology), rabbit polyclonal anti-major urinary

TABLE 1

Sequences of primers used in the study

\begin{tabular}{|c|c|c|}
\hline Gene & Sense $\left(5^{\prime} \rightarrow 3^{\prime}\right)$ & Antisense $\left(5^{\prime} \rightarrow 3^{\prime}\right)$ \\
\hline pCAGGS common sequence & acataacttacggtaaatggc & gatgactaatacgtagatgta \\
\hline Mouse prolactin cDNA insert & catcattttggcaaagaattc & tttatcgaattcaatgaacat \\
\hline Gapdh & tgtgtccgtcgtggatctga & ttgctgttgaagtcgcaggag \\
\hline Prl & atgaccatgaacagccaggggtcagc & ttagcagttgttttgatgggcaattt \\
\hline Сур 3 a16 & agcaccgcgtggactttatt & gggctgtgatctcgatttcag \\
\hline Сур $3 a 41$ & gccaaagggattttaagagttgact & ggtgtcaggaatggaaaaagtaca \\
\hline Сур $3 a 44$ & atccccaaagggtcaatggtg & agggcagatatacgtaaggatca \\
\hline Cур $2 a 4$ & agcaggctaccttcgactgg & gctgctgaaggctatgccat \\
\hline Сур $2 b 9$ & caccaggaccccatcctcta & ttcttgaagctgaatgaaacact \\
\hline Prlr & cacagtaaatgccacgaacg & ggcaaccattttacceacag \\
\hline Сур $2 d 9$ & agtctctggcttaattcctgat & cgcaagagtatcgggaatgc \\
\hline Cур 7 b1 & tgaggttctgaggctgtgctc & tcctgcacttctcggatgatg \\
\hline Mup1 & caaacagaaaggctggtga & ttgtgcaaacctttccttga \\
\hline Alas 2 & gccattgtcctttcatgctgt & atgaatggcttcgggtggtt \\
\hline Mcm10 & gagttccccaggttggaagg & gcgctcagttttggtcttgg \\
\hline Nox4 & ggggttaaacacctctgcct & caggactgtccggcacatag \\
\hline Cypla2 & ggaggctaaccatctcgtca & ggcaccaatgacgttagcca \\
\hline Cур 3 a11 & tcacacacacagttgtagggagaa & gtccatccetgcttgtttgtc \\
\hline Сур 3 a 13 & accggcggcgcttt & attctcagagatagagatggcctttt \\
\hline Сур $3 a 25$ & cttcactgtccagccttgtgaa & aattggttccetgctgatcttc \\
\hline Cyp19a1 & tcatggtcccggaaactgtg & atcaggagaaggaggcccat \\
\hline Cyp27al & tccaatgtggacaacctcct & atcacttgctccaagagtggg \\
\hline Igf-1 & tgtaaacgacccggacctac & cacgaactgaagagcatcca \\
\hline$G h r$ & ccaactcgcctctacaccg & gggaaaggactacaccacctg \\
\hline
\end{tabular}


proteins (Mups) antibody (sc-66976, $1.0 \mu \mathrm{g} / \mathrm{ml}$; Santa Cruz Biotechnology, Dallas, TX), or horseradish-conjugated goat polyclonal anti-albumin antibody (ab19195, $0.05 \mu \mathrm{g} / \mathrm{ml}$; Abcam, Cambridge, MA). Normal goat polyclonal IgG was used as a control IgG against anti-PrlR. Horseradish peroxidase-conjugated specific secondary antibody was then reacted with anti-PrlR, anti-Stat5, anti-phospho-Stat5, anti-MUPs antibody, or control $\mathrm{IgG}$, respectively. Signals were detected using Pierce Western Blotting Substrate Plus (Thermo Fisher Scientific, Waltham, MA).

Real-Time Quantitative Polymerase Chain Reaction Analysis. Total RNA was extracted from each liver using the RNeasy Mini Kit (Qiagen, Valencia, CA). Real-time quantitative polymerase chain reaction (qPCR) analysis was performed using the Thermal Cycler Dice Real Time System II with One Step SYBR PrimeScript Plus RT-PCR Kit (Takara Bio, Shiga, Japan) following the manufacturer's protocol. For relative quantification analysis, target amplicons and Gapdh were reverse transcribed and quantified using the same template RNA. The primer sequences are shown in Table 1.

Statistical Analysis. Values are expressed as mean \pm S.D. Statistical differences were calculated with Student's $t$ test for comparison between two groups. For comparison among four groups one-way analysis of variance was used, followed by Scheffe's F test as a post-hoc test. $P<0.05$ was considered significant.

\section{Results}

Induction of Hyperprolactinemia by Gene Transfer. To reproduce continuously high levels of serum prolactin, we constructed an expression plasmid vector by inserting mouse prolactin cDNA into pCAGGS (pCAGGS-mPrl) and then transfected it into mice hepatocytes by hydrodynamic injection. After the hydrodynamic injection of the vector into the male or female mice, we extracted liver DNA from the mice and confirmed the transfection of the vector into the hepatocytes by PCR using a primer pair specific for the pCAGGS vector sequence and mouse prolactin cDNA (Fig. 1A). We also extracted the total RNA from the liver of these mice and, by reverse transcription PCR with primers specific for mouse prolactin, confirmed the mouse prolactin mRNA expression in the liver of the mice treated with pCAGGS-mPrl (Fig. 1B). The serum level of prolactin was significantly elevated in both male and female mice treated with pCAGGS- $m P r l$ compared with that in mice treated with mock vector (Fig. 1C).

Induction of Stat5 Phosphorylation by Hyperprolactinemia. We examined the effect of prolactin on expression of several sex-predominant genes in the liver. The biologic effects of prolactin are mediated by its interaction with PrlR, which is a member of the cytokine receptor superfamily, and is present in nearly all organs and tissues (BoleFeysot et al., 1998; Binart et al., 2010; Tsuchida et al., 2014). Although the PrlR gene is unique in each species, alternative splicing generates different isoforms, which are identical in their extracellular domains but differ in the lengths and sequences of their intracellular domains. PrlR exists as seven recognized isoforms in humans, and in mice, one long and two short isoforms have been identified as proteins, and the short forms only differ by a few amino acids in the C-terminal part of the cytoplasmic tail. Acting through long-form PrlR, prolactin activates many kinases including Jak2/Stat5, whereas short-form PrlRs are reported to have independent biologic activity and to have a signaling pathway distinct from Jak/Stat signaling cascades (Bole-Feysot et al., 1998; Binart et al., 2010). Long-form PrlR was confirmed to be expressed in both male and female liver (Fig. 1D), and phosphorylation of Stat5 was detected in both male and female mice treated with pCAGGS-mPrl (Fig. 1E).

Sex-Predominant Hepatic Gene Expression Was Affected by Hyperprolactinemia. We investigated the effect of hyperprolactinemia on expression of hepatic genes representative of each of the four major classes of mouse sex-specific genes, namely class I and class II malespecific and female-specific genes (Wauthier et al., 2010, Ramirez et al.,

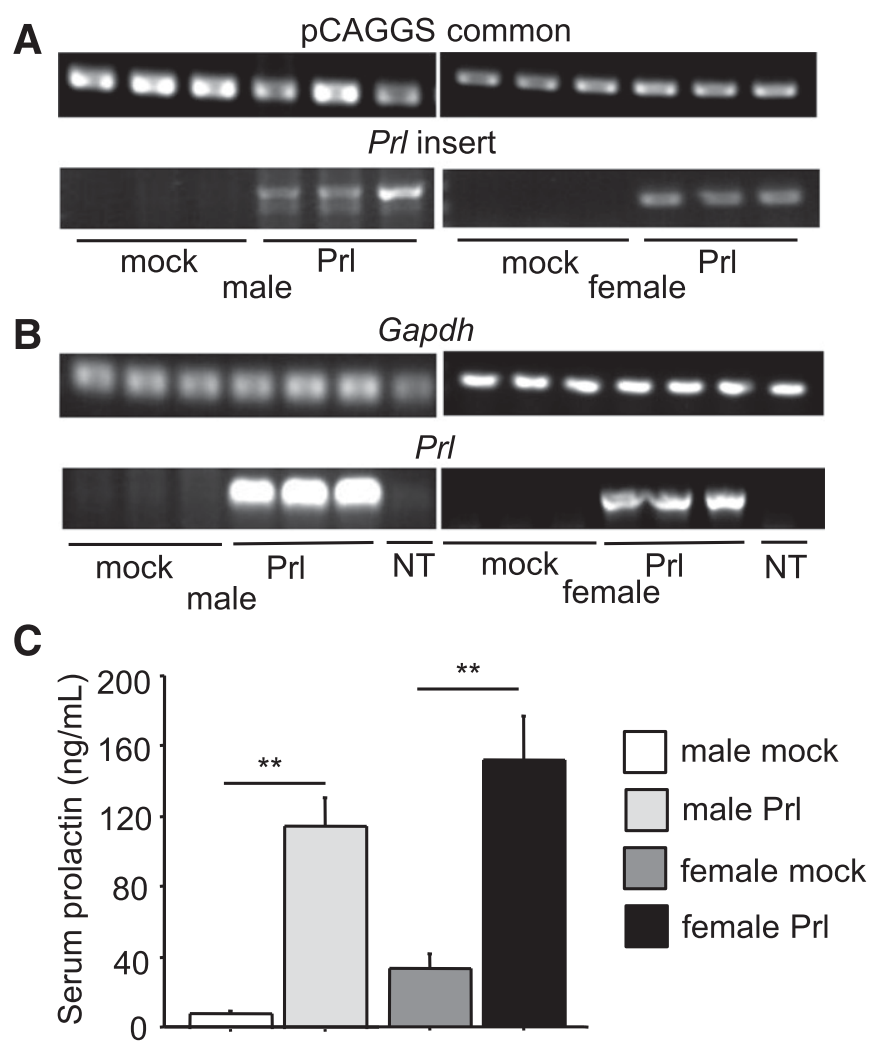

D

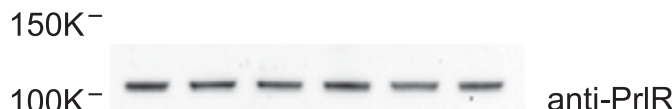

$150 \mathrm{~K}^{-}$

$100 \mathrm{~K}^{-}$

control lgG

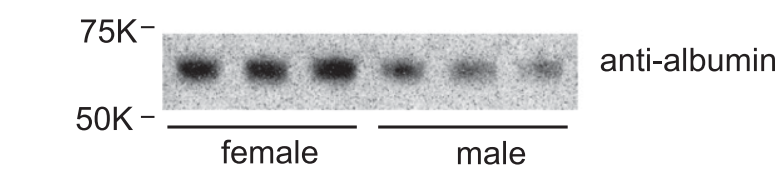

E

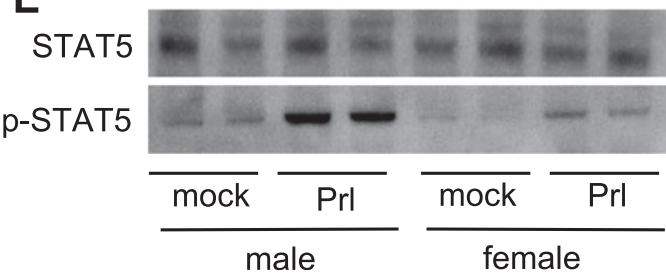

Fig. 1. Prolactin gene transfection by hydrodynamic injection into mouse liver. (A) Expression vector pCAGGS with mouse prolactin cDNA insert (pCAGGS$m P r l$, Prl) or mock vector was transfected into hepatocytes by hydrodynamic method in male or female mice at 10-12 weeks of age, and the transfection of each pCAGGS plasmid was examined 2 days after the injection by amplifying pCAGGS common sequence or mouse $P r l$-specific sequence using DNA extracted from the liver. (B) Murine Prl and Gapdh mRNA expression in the liver was examined 2 days after the injection by reverse transcription PCR after hydrodynamic injection of the pCAGGS- $m P r l$ or mock vector; NT, mRNA from the liver of the mouse with no treatment. (C) Serum concentration of prolactin in male and female mice 2 days after the injection of pCAGGS- $m P r l(\operatorname{Prl})$ or mock vector $(n=4)$. (D) Expression of PrlR in hepatocyte of female and male mice. PrlR in hepatocytes was detected in both male and female mice by Western blot. Albumin was reacted as a loading control. Normal goat $\operatorname{IgG}$ was used as a control IgG. (E) Phosphorylation of Stat5 in hepatocyte in male and female mice 2 days after injection of pCAGGS- $m P r l(\operatorname{Prl})$ or mock vector. $* * P<0.01$. Error bars indicate S.D. 
2015). Figure $2 \mathrm{~A}$ demonstrates that mRNA expression of such female class I genes as Cyp3a16, Cyp3a41, and Cyp3a44 were dramatically augmented by hyperprolactinemia, especially in female mice. Female class II gene Cyp $2 a 4$ expression was increased in male mice alone, whereas other female class II genes, Cyp $2 b 9$ and Prlr, were increased in expression exclusively in female mice (Fig. 2B). Male class I genes, such as $C y p 2 d 9, C y p 7 b 1$, and Mupl were male predominantly expressed at basal level and were downregulated by hyperprolactinemia, especially in male mice (Fig. 2C), whereas such male class II genes as Alas2, Mcm10, and Nox4 were also male-predominantly expressed at basal level, but only Alas 2 was downregulated by hyperprolactinemia in male mice (Fig. 2D). Cypla2, male-predominant but not classified as class I or class II, was upregulated in male mice at both basal and hyperprolactinemic condition but was not affected by hyperprolactinemia. Other unclassified genes, such as Cyp3a11, Cyp3a13, Cyp3a25, Cyp19a1, and Cyp27a1, did not differ in expression between male and female mice and were not affected by prolactin (Fig. 2E). The serum Mup levels were decreased in hyperprolactinemic male mice (Fig. 2F).

Hyperprolactinemia Did Not Influence the Serum Levels of GH or TT. Since expression of these sex-specific hepatic genes is regulated by $\mathrm{GH}$, and some of them are also affected by testosterone (Delić et al., 2010; Knopf et al., 1983), we verified the influence of hyperprolactinemia on serum levels of GH and TT. In both male and female mice treated with pCAGGS-mPrl, the serum levels of GH were not significantly
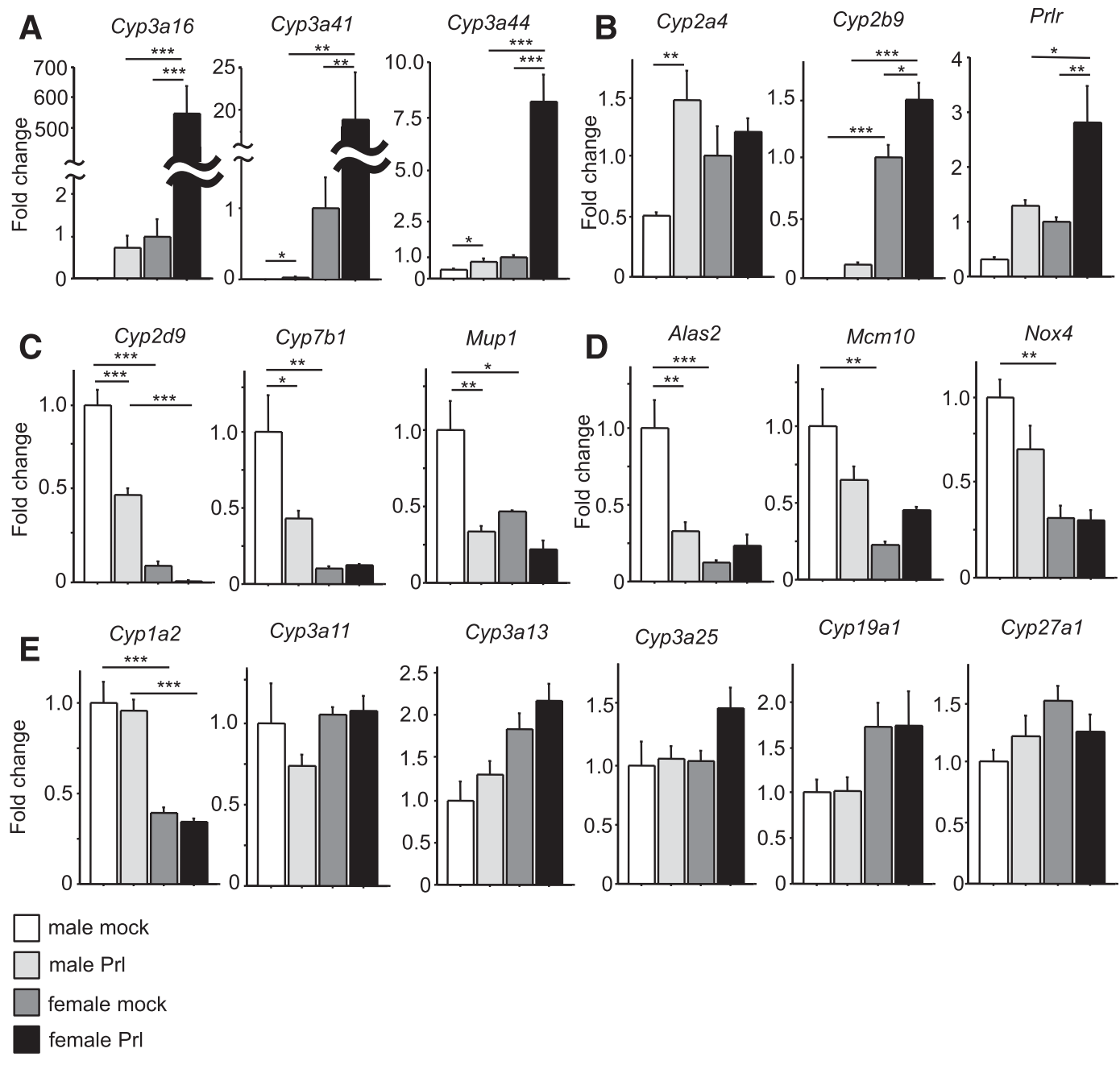

Сур3а13

Cyp3a25

Cyp19a1

Cyp27a1
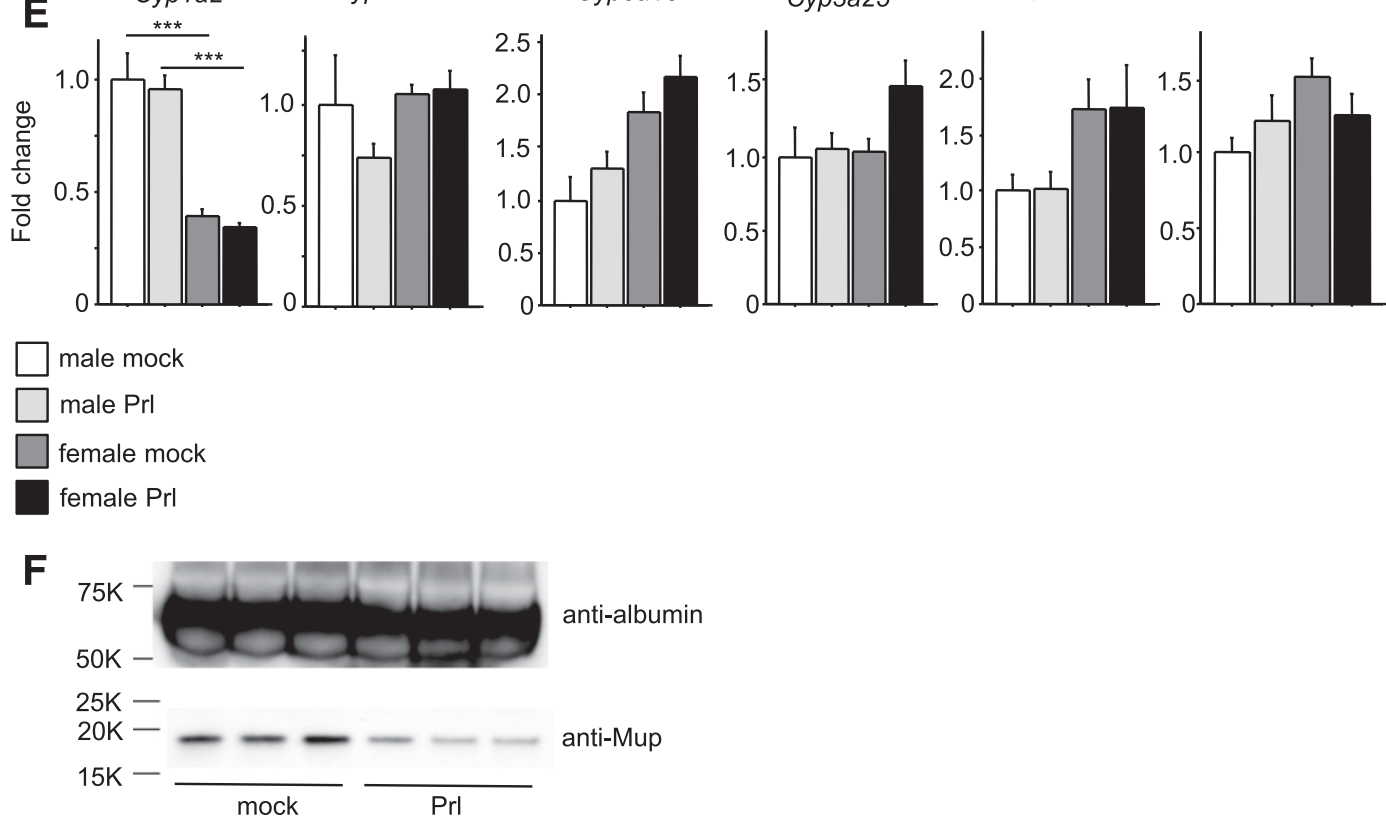

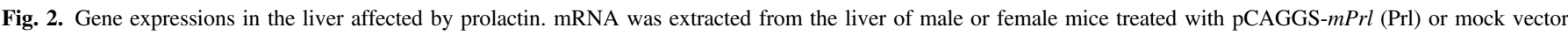

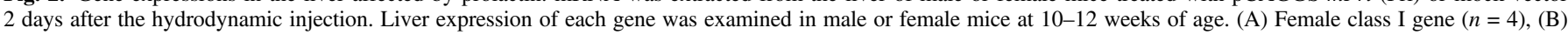

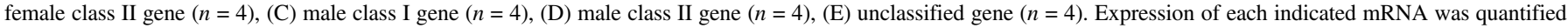

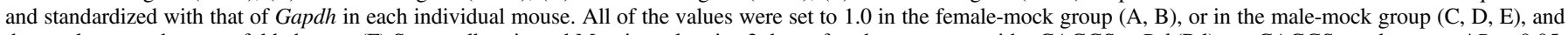

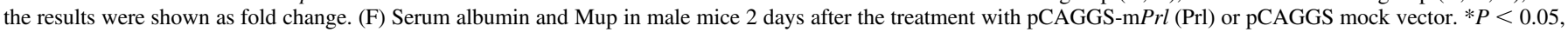
$* * P<0.01, * * * P<0.001$. Error bars indicate S.D. 
different from those in mice treated with pCAGGS-mock. In female mice, TT concentration was below the detectable level, and serum levels of TT in male mice were not affected by hyperprolactinemia (Fig. 3A). To examine the effect of $\mathrm{GH}$ in the liver, liver mRNA expression of insulin-like growth factor (Igf)-1, which is mainly induced by GH (Chia, 2014), was evaluated in both male and female mice treated with pCAGGS- $m P r l$ or its mock vector. The results showed that the Igf-I expression was not affected by hyperprolactinemia in both male and female mice. Ghr mRNA expressions were not affected by hyperprolactinemia either (Fig. 3B), indicating that GH-GHR interaction in the liver was not affected by elevated serum prolactin level.

\section{Discussion}

In this study, several lines of evidence showed that prolactin upregulated mRNA expression of some female-predominant class I and class II genes, such as Cyp3a16, Cyp3a41, Cyp3a44, Cyp2b9, and Prlr, in female mice liver and induced downregulation of expression of malepredominant class I and part of class II genes, such as Cyp2d9, Cyp $7 b 1$, Mup1, and Alas2, in male mice liver. Female class I gene expressions especially were dramatically elevated by prolactin treatment in female mice liver.

Female class I genes, such as Cyp3a16, Cyp3a41 and Cyp3a44, are female-predominant murine $C y p 3 a$ isoforms expressed in the liver that

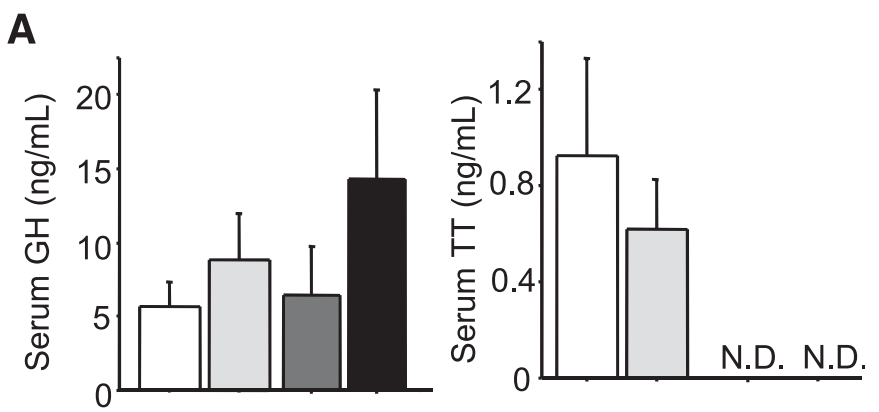

B

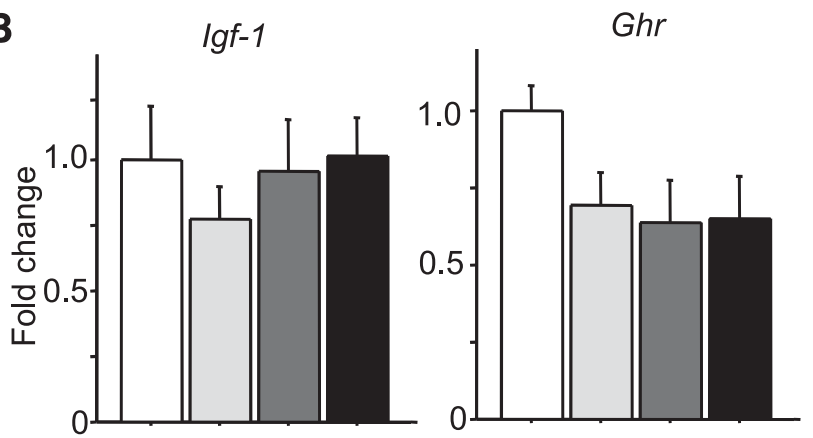

male mock

male $\mathrm{Prl}$

female mock

\section{female $\mathrm{Prl}$}

Fig. 3. Effect of prolactin on serum GH and TT. (A) Serum concentrations of GH and TT of male and female mice were examined 2 days after the treatment with pCAGGS-mPrl $(\mathrm{Prl})$ or pCAGGS mock vector at 10-12 weeks of age $(n=4)$. (B) mRNA was extracted from the liver of male or female mice 2 days after the treatment with pCAGGS-mPrl (Prl) or pCAGGS mock vector. Igf- 1 and $G h r$ mRNA expressions were quantified and standardized with that of Gapdh in each mouse. The values were set to 1.0 in the male mock group and the results were shown as fold change $(n=4)$. Error bars indicate S.D. N.D., not detected. belong to class IA liver genes defined as positively regulated by the female but not male GH secretory profile (Ramirez et al., 2015). $P 450$ s are conveniently arranged into families and subfamilies on the basis of the percentage of amino acid sequence identity, with $C Y P 2$, $C Y P 3$, and $C Y P 4$ families containing far more genes than the other families in humans and mice (Nebert et al., 2013). Murine Cyp $3 a$ is a subfamily of six isoforms, Cyp3a11 (Yanagimoto et al., 1992), Cyp3a13 (Yanagimoto et al., 1994), Cyp3a16 (Itoh et al., 1994), Cyp3a25 (Dai et al., 2001), Cyp3a41 (Sakuma et al., 2000), and Cyp3a44 (Sakuma et al., 2002). Cyp3a16 expression is detected in mice fetal liver and starts to decrease after 2 weeks of age, and only a small amount is detectable at 5 weeks of age (Itoh et al., 1994). In contrast, Cyp $3 a 41$ is constantly expressed after birth in female mice, whereas Cyp3a44 expression increases with age in female mice after 3 weeks of age. In male mice, the expression of both Cyp3a41 and Cyp $3 a 44$ gradually declines after 5 weeks of age (Sakuma et al., 2002). GH was determined as the inducer of hepatic Cyp3a16, Cyp3a41, and Cyp3a44 mRNA expressions (Sakuma et al., 2002, 2008; Ramirez et al., 2015). During pregnancy, PGH levels increase continuously and replace the pituitary GH. PGH differs from GH by only 13 amino acid residues and they both bind to the same GHR with similar affinity. GH-GHR signaling induces hepatocyte nuclear factor 6 and upregulates Cyp3a41 expression in mice and CYP3A4 in humans. Mouse plasma estradiol concentration is also elevated during pregnancy and has been reported to induce the liver Cyp3a16, Cyp $3 a 41$, and Cyp3a44 expression, and this upregulation is correlated with estrogen receptor- $\alpha$ transcripts. Increased PGH and estrogen were believed to activate the transcription of Cyp3a41 and Cyp3a44 in a synergistic manner during pregnancy (Zhang et al., 2008).

Recently, Ramirez et al. (2015) demonstrated high prolactin levels and an increase in the Cyp3a16, Cyp3a44, and Cyp3a41 mRNA expressions without a change in pituitary $\mathrm{GH}$ and serum IGF-1 levels in female mice that genetically lacked dopamine 2 receptors (D2R) in lactotrophs. In contrast, Mup mRNA levels were decreased in the liver of male and female mice that genetically lacked D2R in neurons, resulting in reduction of pituitary GH and serum IGF-1, but not serum prolactin (Ramirez et al., 2015). In the present study, prolactin was revealed to be the independent inducer of hepatic Cyp3a16, Cyp3a41, and Cyp3a44 mRNA expression in female mice. Considering that prolactin is secreted mainly from the pituitary gland and shares similar amino acid sequence and structural and biologic features with GH (Freeman et al., 2000), it is not contradictory that prolactin exhibits an effect similar to that of the continuous GH secretion on Cyp3a16, Cyp3a41, and Cyp3a44 induction. However, unlike the continuous $\mathrm{GH}$, hyperprolactinemia induced hepatic Stat5 phosphorylation, in common with the pulsatile $\mathrm{GH}$, resulting in alteration of hepatic gene transcriptions. It is still to be elucidated how the different gene expressions of prolactin and $\mathrm{GH}$ could be induced by the same Stat5 phosphorylation and activation.

We could not completely exclude the possibility that hyperprolactinemia altered the episodic $\mathrm{GH}$ secretion pattern in male mice, but serum $\mathrm{GH}$ level and liver $I g f-1$ mRNA level were not significantly altered. In addition, Cyp3a16, Cyp3a41, and Cyp3a44 induction was observed in female mice whose GH secretion pattern was continuous, suggesting that the effect of prolactin is independent of the influence of the $\mathrm{GH}$ secretion pattern. GH receptor mRNA expression in liver of both male and female mice was not affected by hyperprolactinemia, suggesting that the influence on GH-GHR interaction was nominal in this hyperprolactinemia model. However, prolactin alone could not induce expression of female-predominant genes in the female human hepatocytes in vitro (Lee et al., 2014). We conjecture that induction of female-predominant genes by prolactin requires several other factors coexisting in the serum in vivo. 
Prior studies have reported that a proestrous surge of prolactin did not change hepatic P450 expression and Stat5 activity, and that neither ablation of prolactin by bromocriptine nor direct injection of prolactin affected hepatic Stat5 activity (Choi and Waxman, 1999; Lee et al., 2012). Considering the short duration of proestrous prolactin surge, which consists of 2 hours of an early peak (350-550 ng/ml) and a following 4 hours of a lower plateau (250-300 ng/ml) (Murai et al., 1989), and the rapid metabolic clearance of prolactin in the rat, in which half-life time of prolactin was 3.9-5.2 minutes (Koch et al., 1971), or in the human (Sievertsen et al., 1980), it is not contradictory that a proestrous surge of prolactin or direct injection of prolactin, as well as a continuous basal level of prolactin that could be ablated by bromocriptine, did not influence the upregulation of expression of femalepredominant $P 450$ genes or Stat 5 activation in the liver. Either condition might require continuous exposure of high-level prolactin, considering that hydrodynamics-based cDNA transfection into the liver leads to targeted protein synthesis 8 hours after the injection and continuously produces the protein for at least 6 days (Liu et al., 1999).

We also revealed that prolactin acted as an inhibitor of expression of male-predominant gene, including Mupl in male mice. Mup is a pheromone carrier protein of the lipocalin family secreted in rodent urine and also acts as a pheromone itself (Finlayson et al., 1965; Beynon and Hurst, 2004; Chamero et al., 2007), and is positively regulated by testosterone or pulsatile GH secretion. (Finlayson et al., 1965; Szoka and Paigen, 1978). In contrast, continuous GH secretion and chronic occupancy of GHR lead to inhibitory production of Mups (Norstedt and Palmiter, 1984). Prolactin has been reported to influence testosterone biosynthesis by altering the sensitivity of Leydig cells to the luteinizing hormone and to decrease serum testosterone level in rams (Sanford and Baker, 2010). In the present study, however, the level of serum GH and TT was not significantly decreased in male mice. Therefore, we conjectured that the effect of prolactin on male-predominant gene expression, including Mup in the liver, is independent of both testosterone and $\mathrm{GH}$.

In humans, prolactin secretion is increased in several physiologic and pathologic conditions. During pregnancy, placental estrogen production stimulates lactotroph mitosis and prolactin synthesis, leading to a stepwise increase in serum prolactin levels that achieves mean levels of $200 \mathrm{ng} / \mathrm{ml}$ by the end of pregnancy and a maximal level of $450 \mathrm{ng} / \mathrm{ml}$ in some cases. Serum prolactin levels decline quickly after delivery but are maintained slightly increased in nursing woman, especially after breastfeeding (Bronstein, 2016). Hyperprolactinemia is the most prevalent hypothalamic-pituitary dysfunction, with prolactinomas being the main cause. Microprolactinomas (diameter $<10 \mathrm{~mm}$ ) represent about $60 \%$ of prolactin-secreting adenomas and are more common in women than in men (20:1), whereas macroadenomas have roughly the same prevalence in both genders, and there are no sex-related differences in autopsy series. Serum prolactin usually ranges from 50 to $300 \mathrm{ng} / \mathrm{ml}$ in the presence of microprolactinoma and from 200 to $5000 \mathrm{ng} / \mathrm{ml}$ in the presence of macroprolactinoma (normal values range from 2 to $15 \mathrm{ng} / \mathrm{ml}$ ). Dopamine receptor blockers such as sulpiride, haloperidol, chlorpromazine, metoclopramide, or domperidone are the most frequent cause of pharmacologic hyperprolactinemia, in which serum prolactin increases to levels usually detected with prolactinomas (Bronstein, 2016). Even though a physiologic increase in prolactin level is specific for females, in some pathologic conditions males could also be susceptible to hyperprolactinemia.

To conclude, we demonstrated the regulatory roles of prolactin in sex-predominant expression of hepatic genes. Unlike rodents, during human pregnancy high levels of circulating prolactin are well established (Egli et al., 2010). Prolactin has been shown to regulate expression of various hepatic drug-metabolizing enzymes, such as uridine 5'-diphospho-glucuronosyltransferase 1-6 and glutathione $S$-transferase, resulting in an increase of glutathione conjugation and glucuronidation of $p$-nitrophenol (Jeong, 2010). Alteration of hepatic $P 450$ expression induced by hyperprolactinemia would be one of the causes of altered hepatic drug metabolism in human during pregnancy and lactation.

\section{Acknowledgments}

The authors are grateful for technical support from Naofumi Imai, Kaori Takahashi, Akiko Seino, and Takae Watanabe in the Division of Clinical Nephrology and Rheumatology, Niigata University Graduate School of Medical and Dental Sciences.

\section{Authorship Contributions}

Participated in research design: Sato, Kaneko, Cho, K Goto, Otsuka, Narita. Conducted experiments: Sato, Kaneko, Cho.

Contributed new reagents or analytic tools: Sato, Kaneko, Cho, Maruyama. Performed data analysis: Sato, Kaneko, Cho.

Wrote or contributed to the writing of the manuscript: Sato, Kaneko, Cho, Yamamoto, S Goto, Maruyama, Narita.

\section{References}

Bachelot A and Binart N (2007) Reproductive role of prolactin. Reproduction 133:361-369. Beynon RJ and Hurst JL (2004) Urinary proteins and the modulation of chemical scents in mice and rats. Peptides 25:1553-1563.

Binart N, Bachelot A, and Bouilly J (2010) Impact of prolactin receptor isoforms on reproduction. Trends Endocrinol Metab 21:362-368.

Bole-Feysot C, Goffin V, Edery M, Binart N, and Kelly PA (1998) Prolactin (PRL) and its receptor: actions, signal transduction pathways and phenotypes observed in PRL receptor knockout mice. Endocr Rev 19:225-268.

Bronstein MD (2016) Disorders of prolactin secretion and prolactinomas, in Endocrinology: Adult and Pediatric, 7th ed (Jameson JL and De Groot LJ eds) pp 104-128, Elsevier, Philadelphia.

Chamero P, Marton TF, Logan DW, Flanagan K, Cruz JR, Saghatelian A, Cravatt BF, and Stowers L (2007) Identification of protein pheromones that promote aggressive behaviour. Nature 450 : 899-902.

Chia DJ (2014) Minireview: mechanisms of growth hormone-mediated gene regulation. Mol Endocrinol 28:1012-1025.

Choi HK and Waxman DJ (1999) Growth hormone, but not prolactin, maintains low-level activation of STAT5a and STAT5b in female rat liver. Endocrinology 140:5126-5135.

Corbacho AM, Martínez De La Escalera G, and Clapp C (2002) Roles of prolactin and related members of the prolactin/growth hormone/placental lactogen family in angiogenesis. J Endocrinol 173:219-238.

Dai D, Bai R, Hodgson E, and Rose RL (2001) Cloning, sequencing, heterologous expression, and characterization of murine cytochrome $\mathrm{P} 4503 \mathrm{a} 25 *(\mathrm{Cyp} 3 \mathrm{a} 25)$, a testosterone $6 \beta$-hydroxylase. $J$ Biochem Mol Toxicol 15:90-99.

Delić D, Gailus N, Vohr HW, Dkhil M, Al-Quraishy S, and Wunderlich F (2010) Testosteroneinduced permanent changes of hepatic gene expression in female mice sustained during Plasmodium chabaudi malaria infection. J Mol Endocrinol 45:379-390.

Egli M, Leeners B, and Kruger THC (2010) Prolactin secretion patterns: basic mechanisms and clinical implications for reproduction. Reproduction 140:643-654.

Finlayson JS, Asofsky R, Potter M, and Runner CC (1965) Major urinary protein complex of normal mice: origin. Science 149:981-982.

Freeman ME, Kanyicska B, Lerant A, and Nagy G (2000) Prolactin: structure, function, and regulation of secretion. Physiol Rev 80:1523-1631.

Grosvenor CE and Whitworth N (1974) Evidence for a steady rate of secretion of prolactin following suckling in the rat. J Dairy Sci 57:900-904.

He XJ, Ejiri N, Nakayama H, and Doi K (2005) Changes in cytochrome P450 isozymes (CYPs) protein levels during lactation in rat liver. Exp Mol Pathol 79:224-228.

Itoh S, Satoh M, Abe Y, Hashimoto H, Yanagimoto T, and Kamataki T (1994) A novel form of mouse cytochrome P450 3A (Cyp3a-16). Its cDNA cloning and expression in fetal liver. Eur J Biochem 226:877-882.

Jeong H (2010) Altered drug metabolism during pregnancy: hormonal regulation of drugmetabolizing enzymes. Expert Opin Drug Metab Toxicol 6:689-699.

Kennett JE and McKee DT (2012) Oxytocin: an emerging regulator of prolactin secretion in the female rat. $J$ Neuroendocrinol 24:403-412.

Knopf JL, Gallagher JF, and Held WA (1983) Differential, multihormonal regulation of the mouse major urinary protein gene family in the liver. Mol Cell Biol 3:2232-2240.

Koch Y, Chow YF, and Meites J (1971) Metabolic clearance and secretion rates of prolactin in the rat. Endocrinology 89:1303-1308.

Koh KH, Xie H, Yu AM, and Jeong H (2011) Altered cytochrome P450 expression in mice during pregnancy. Drug Metab Dispos 39:165-169.

Lee JK, Chung HJ, Fischer L, Fischer J, Gonzalez FJ, and Jeong H (2014) Human placental lactogen induces CYP2E1 expression via PI 3-kinase pathway in female human hepatocytes. Drug Metab Dispos 42:492-499.

Lee SY, Oh SJ, Yun KU, Kim HM, Kim BH, Lee K, and Kim SK (2012) Expression of hepatic and ovarian cytochrome P450 during estrous cycle in rats. Arch Toxicol 86:75-85.

Liu F, Song Y, and Liu D (1999) Hydrodynamics-based transfection in animals by systemic administration of plasmid DNA. Gene Ther 6:1258-1266.

Moore KE (1987) Interactions between prolactin and dopaminergic neurons. Biol Reprod 36: $47-58$. 
Murai I, Reichlin S, and Ben-Jonathan N (1989) The peak phase of the proestrous prolactin surge is blocked by either posterior pituitary lobectomy or antisera to vasoactive intestinal peptide. Endocrinology 124:1050-1055.

Nebert DW, Wikvall K, and Miller WL (2013) Human cytochromes P450 in health and disease. Philos Trans $R$ Soc Lond B Biol Sci 368:20120431.

Waxman DJ, Attisano C, Guengerich FP, and Lapenson DP (1988) Human liver microsomal steroid metabolism: identification of the major microsomal steroid hormone $6 \beta$-hydroxylase cytochrome P-450 enzyme. Arch Biochem Biophys 263:424-436.

Niwa H, Yamamura K, and Miyazaki J (1991) Efficient selection for high-expression transfectants with a novel eukaryotic vector. Gene 108:193-199.

Norstedt G and Palmiter R (1984) Secretory rhythm of growth hormone regulates sexual differentiation of mouse liver. Cell 36:805-812.

Ramirez MC, Ornstein AM, Luque GM, Perez Millan MI, Garcia-Tornadu I, Rubinstein M, and Becu-Villalobos D (2015) Pituitary and brain dopamine D2 receptors regulate liver gene sexual dimorphism. Endocrinology 156:1040-1051.

Sakuma T, Bhadhprasit W, Hashita T, and Nemoto N (2008) Synergism of glucocorticoid hormone with growth hormone for female-specific mouse Cyp3a44 gene expression. Drug Metab Dispos 36:878-884.

Sakuma T, Endo Y, Mashino M, Kuroiwa M, Ohara A, Jarukamjorn K, and Nemoto N (2002) Regulation of the expression of two female-predominant CYP3A mRNAs (CYP3A41 and CYP3A44) in mouse liver by sex and growth hormones. Arch Biochem Biophys 404:234-242.

Sakuma T, Takai M, Endo Y, Kuroiwa M, Ohara A, Jarukamjorn K, Honma R, and Nemoto N (2000) A novel female-specific member of the CYP3A gene subfamily in the mouse liver. Arch Biochem Biophys 377:153-162.

Sanford LM and Baker SJ (2010) Prolactin regulation of testosterone secretion and testes growth in DLS rams at the onset of seasonal testicular recrudescence. Reproduction 139:197-207.

Shimada T, Yamazaki H, Mimura M, Inui Y, and Guengerich FP (1994) Interindividual variations in human liver cytochrome P-450 enzymes involved in the oxidation of drugs, carcinogens and toxic chemicals: studies with liver microsomes of 30 Japanese and 30 Caucasians. J Pharmacol Exp Ther 270:414-423.

Sievertsen GD, Lim VS, Nakawatase C, and Frohman LA (1980) Metabolic clearance and secretion rates of human prolactin in normal subjects and in patients with chronic renal failure. $J$ Clin Endocrinol Metab 50:846-852.

Sugimoto H and Shiro Y (2012) Diversity and substrate specificity in the structures of steroidogenic cytochrome P450 enzymes. Biol Pharm Bull 35:818-823.

Szoka PR and Paigen K (1978) Regulation of mouse major urinary protein production by the Mup-A gene. Genetics 90:597-612.

Tonkowicz P, Robertson M, and Voogt J (1983) Secretion of rat placental lactogen by the fetal placenta and its inhibitory effect on prolactin surges. Biol Reprod 28:707-716.
Tracy TS, Venkataramanan R, Glover DD, and Caritis SN; National Institute for Child Health and Human Development Network of Maternal-Fetal-Medicine Units (2005) Temporal changes in drug metabolism (CYP1A2, CYP2D6 and CYP3A Activity) during pregnancy. Am J Obstet Gynecol 192:633-639.

Tsuchida Y, Kaneko Y, Otsuka T, Goto K, Saito A, Yamamoto K, Yamamoto T, and Narita I (2014) Upregulation of prolactin receptor in proximal tubular cells was induced in cardiac dysfunction model mice. Clin Exp Nephrol 18:65-74.

Voogt J, Robertson M, and Friesen H (1982) Inverse relationship of prolactin and rat placental lactogen during pregnancy. Biol Reprod 26:800-805.

Wauthier V and Waxman DJ (2008) Sex-specific early growth hormone response genes in rat liver. Mol Endocrinol 22:1962-1974.

Wauthier V, Sugathan A, Meyer RD, Dombkowski AA, and Waxman DJ (2010) Intrinsic sex differences in the early growth hormone responsiveness of sex-specific genes in mouse liver. $M o$ Endocrinol 24:667-678.

Waxman DJ and Holloway MG (2009) Sex differences in the expression of hepatic drug metabolizing enzymes. Mol Pharmacol 76:215-228.

Waxman DJ and O'Connor C (2006) Growth hormone regulation of sex-dependent liver gene expression. Mol Endocrinol 20:2613-2629.

Waxman DJ, Attisano C, Guengerich FP, and Lapenson DP (1988) Human liver microsomal steroid metabolism: identification of the major microsomal steroid hormone $6 \beta$-hydroxylase cytochrome P-450 enzyme. Arch Biochem Biophys 263:424-436.

Yanagimoto T, Itoh S, Muller-Enoch D, and Kamataki T (1992) Mouse liver cytochrome $P$-450 (P450IIIA $\mathrm{A}_{\mathrm{M} 1}$ ): its cDNA cloning and inducibility by dexamethasone. Biochim Biophys Acta 1130 . 329-332.

Yanagimoto T, Itoh S, Sawada M, Hashimoto H, and Kamataki T (1994) Molecular cloning and functional expression of a mouse cytochrome $P-450$ (Cyp3a-13): examination of Cyp3a-13 enzyme to activate aflatoxin $\mathrm{B}_{1}\left(\mathrm{AFB}_{1}\right)$. Biochim Biophys Acta 1201:405-410.

Zhang H, Wu X, Wang H, Mikheev AM, Mao Q, and Unadkat JD (2008) Effect of pregnancy on cytochrome $\mathrm{P} 450 \mathrm{3a}$ and P-glycoprotein expression and activity in the mouse: mechanisms, tissue specificity, and time course. Mol Pharmacol 74:714-723.

Address correspondence to: Dr. Yoshikatsu Kaneko, Division of Clinical Nephrology and Rheumatology, Niigata University Graduate School of Medical and Dental Sciences, 1-757 Asahimachi-dori, Niigata 9518510, Japan. E-mail: kanekoy@med.niigata-u.ac.jp 